\title{
QUALIDADE DA MADEIRA DE CINCO ESPÉCIES DE OCORRÊNCIA NO CERRADO PARA PRO- DUÇÃO DE CARVÃO VEGETAL
}

Tattiane Gomes Costa $^{1}$, Maria Lúcia Bianchi ${ }^{1}$, Thiago de Paula Protásioํㄹ Paulo Fernando Trugilho ${ }^{1}$, Ariclene Júnior

*Autor para correspondência: tatti_gcosta@yahoo.com.br

\author{
Pereira $^{1}$
}

RESUMO: Este trabalho teve como objetivo avaliar a qualidade da madeira e do carvão vegetal de algumas espécies de ocorrência do cerrado mineiro visando o uso siderúrgico. Foram utilizadas cinco espécies de madeiras de ocorrência no cerrado procedentes do Estado de Minas Gerais. Na madeira foram avaliadas a densidade básica e os teores de lignina, extrativos totais, holocelulose e cinzas. No carvão vegetal foram avaliados os rendimentos em carvão vegetal e em carbono fixo, os teores de carbono fixo, materiais voláteis e cinzas, o poder calorífico superior e a densidade relativa aparente. Na avaliação do experimento utilizou-se o delineamento inteiramente casualizado com quatro repetições. Utilizou-se ainda a análise multivariada de componentes principais. As espécies Casearia sylvestris e Luehea divaricata apresentaram os maiores rendimentos gravimétricos em carvão vegetal e em carbono fixo, bem como elevados teores de lignina na madeira. O carvão vegetal da espécie Trema micrantha possui elevado poder calorífico superior, mas a menor densidade relativa aparente. A espécie Guazuma ulmifolia se destacou pelo elevado teor de carbono fixo e grande potencial para uso siderúrgico, juntamente com a espécie Casearia sylvestris.

Palavras-chave: carvão vegetal, espécies nativas, qualidade da madeira

\section{WOOD QUALITY OF FIVE SPECIES FROM CERRADO FOR PRODUCTION OF CHARCOAL}

\begin{abstract}
The aim of this research was to evaluate the quality of wood and charcoal of some species from cerrado mineiro aiming the production of bioenergy and use in steel industry. Five wood species from cerrado located in Minas Gerais state were used. Basic density and lignin, total extractives, holocellulose and ash contents were evaluated. Charcoal and fixed carbon yields, contents of fixed carbon, volatile materials and ashes, higher heating value and apparent relative density were evaluated. An entirely randomized design with four repetitions was used in the evaluation of the experiment. Moreover, multivariate analysis of principle components was used. The species Casearia sylvestris and Luehea divaricata had the highest gravimetric yield of charcoal and fixed carbon, as much as high lignin contents in the wood. Charcoal made from Trema micrantha presented high heating value, but the lowest apparent relative density. The species Guazuma ulmifolia stood out due to high fixed carbon content and great potential for use in the steel industry, together with the specie Casearia sylvestris.
\end{abstract}

Key words: charcoal, native species, wood quality

\section{INTRODUÇÃO}

O Brasil é o maior produtor e consumidor de carvão vegetal do mundo. Este carvão é destinado, principalmente, ao setor siderúrgico. Cerca de $80 \%$ do carvão produzido é consumido na indústria siderúrgica na redução do minério de ferro a ferro-gusa (BRASIL, 2010).

A grande demanda por carvão vegetal para suprir as indústrias siderúrgicas como agente de dupla finalidade (biorredutor e fornecedor de energia) é um dos fatores que contribuem com o desmatamento. Em 2011, as exportações brasileiras de ferro-gusa tiveram um aumento de $40 \%$ em relação a 2010 (ABRAF, 2012). Porém, não há florestas plantadas o suficiente para suprir esta demanda, acarretando na exploração desordenada das matas nativas, principalmente no cerrado mineiro, onde se concentram a maioria das indústrias siderúrgicas no Brasil (ABRAF, 2012). O setor siderúrgico brasileiro ainda utiliza cerca

${ }^{1}$ Universidade Federal de Lavras - Lavras, Minas Gerais, Brasil de $35 \%$ a $50 \%$ de carvão vegetal proveniente de florestas nativas (AGÊNCIA BRASIL, 2010; MMA, 2011; ABRAF, 2012).

As indústrias que usam carvão vegetal terão prazo até 2020 para aumentar o uso desse combustível oriundo de fontes sustentáveis, como as florestas plantadas e a madeira nativa oriunda do plano de manejo florestal sustentável. Essa medida consta no plano de ação para prevenção e controle do desmatamento e das queimadas no cerrado (MMA, 2011). Um dos pontos abordados nesse plano (PPCerrado) é a necessidade de aumento e melhoria do manejo florestal sustentável no cerrado, principalmente para fins energéticos.

Para que seja possível realizar um plano de manejo florestal sustentável (PMFS), primeiramente existe a necessidade de fomentar pesquisas científicas com espécies nativas, levantando informações sobre os recursos

Cerne, Lavras, v. 20, n. 1, p. 37-46, jan./mar. 2014 
florestais disponíveis, o uso sustentável desses recursos, a vegetação nativa, o manejo mais adequado das espécies, o crescimento, a biomassa e o estoque de carbono.

Outro fator importante é a avaliação da qualidade da madeira e do carvão vegetal para averiguação do potencial do material a ser utilizado como insumo energético, uma vez que esse produto sofre influência da madeira que lhe deu origem e do sistema de produção (TRUGILHO et al., 2001; NEVES et al., 2011; SANTOS et al., 2012; PROTÁSIO et al., 2012; PROTÁSIO et al., 2013). Além disso, o estudo anatômico pode ser fundamental no controle do carvão vegetal ilegal (MUÑIZ et al., 2012).

Diante disto, esse trabalho vem contribuir com o PPCerrado, uma vez que visa o estudo (físico, químico e energético) de algumas espécies desse bioma. As informações aqui adquiridas, juntamente com outros temas de pesquisa, poderão, num futuro muito próximo, servir de subsídios para a formulação de políticas públicas de fomento ao manejo florestal e uso sustentável do cerrado para a produção de bioenergia e carvão vegetal.

Neste contexto, o objetivo deste trabalho foi avaliar a qualidade da madeira e do carvão vegetal de algumas espécies de ocorrência no cerrado mineiro visando o uso para fins energéticos.

\section{MATERIAL E MÉTODOS}

\subsection{Material biológico e análises da madeira}

Foram utilizadas cinco espécies de madeiras de ocorrência no cerrado procedentes do Estado de Minas Gerais. As espécies foram: Luehea divaricata Mart., Casearia sylvestris Sw., Guazuma ulmifolia Lam., Rapanea ferruginea (Ruiz \& Pav.) Mez e Trema micranta (L.) Blume. Essas foram selecionadas por serem espécies pioneiras de rápido crescimento e conservação comum.

As árvores foram coletadas na Fazenda Campo Lindo, localizada no acesso $\mathrm{Br} 265$, quilômetro 324 sentido São João Del Rei estrada Cachoeira do Pilão, na Cidade de Itumirim-MG. O bioma típico da região de coleta é Cerrado Sensu Stricto.

Foram amostradas aleatoriamente quatro árvores de cada espécie. De cada árvore foi retirado um torete de $75 \mathrm{~cm}$, a partir da altura de $30 \mathrm{~cm}$ do chão. Os toretes foram seccionados em discos de aproximadamente $5 \mathrm{~cm}$ de espessura. Os discos foram subdivididos em quatro pares de cunhas opostas, sendo utilizado um par de cunhas opostas para determinação da densidade básica e as demais para a carbonização e análise química da madeira.

Cerne, Lavras, v. 20, n. 1, p. 37-46, jan./mar. 2014
Na determinação da densidade básica da madeira foi utilizado o método de imersão segundo a NBR 11941 (ABNT, 2003).

As análises químicas foram realizadas para determinar o teor de lignina Klason, extrativos totais e cinzas. O teor de lignina foi determinado de acordo com o procedimento descrito na M70/71(ABTCP, 1974). A determinação dos teores de extrativos totais foi realizada conforme a M3/69 (ABTCP, 1974a). A quantificação das cinzas ou minerais foi obtida conforme a M11/77 (ABTCP, 1974b). O teor de holocelulose foi obtido por diferença.

\subsection{Carbonização e avaliação da qualidade do carvão vegetal}

Para a carbonização foram utilizados dois pares de cunhas retiradas do disco a um metro da base da árvore. Foram realizadas quatro carbonizações por espécie.

As cunhas utilizadas foram previamente secas em estufa a $103 \pm 2{ }^{\circ} \mathrm{C}$ até massa constante. Em seguida as amostras foram carbonizadas em forno elétrico tipo mufla, a uma taxa de aquecimento de $1,67^{\circ} \mathrm{C} \mathrm{min}^{-1}$, com a temperatura final de carbonização de $450^{\circ} \mathrm{C}$, permanecendo por 30 minutos nessa temperatura. Esse procedimento é usualmente empregado na literatura (TRUGILHO et al., 2001; NEVES et al., 2011; ASSIS et al., 2012; PROTÁSIO et al., 2011; PROTÁSIO et al., 2012). Após as carbonizações foi determinado o rendimento gravimétrico em carvão vegetal (RGC).

A densidade relativa aparente do carvão vegetal foi determinada por meio do método hidrostático, com imersão em água, segundo a NBR 11941 (ABNT, 2003).

Os teores de materiais voláteis, cinzas e de carbono fixo foram determinados conforme a D1762-84 (AMERICAN SOCIETY FOR TESTING MATERIALS, 2007). O rendimento em carbono fixo foi calculado mediante o produto do rendimento gravimétrico em carvão vegetal e o teor de carbono fixo.

Para a determinação do poder calorífico superior (PCS) foi utilizado o calorímetro digital da marca IKA ${ }^{\circledR}$ C-200, segundo a NBR 8633 (ABNT, 1984).

\subsection{Análises estatísticas}

$\mathrm{Na}$ avaliação do experimento utilizou-se o delineamento inteiramente casualizado com quatro repetições e considerando como fator de variação as diferentes espécies (Eq. 1). As médias foram comparadas 
estatisticamente pelo Teste de Scott-Knott em nível de 5\% de significância.

$$
Y_{i j}=\mu+t_{i}+e_{i j}
$$

Em que: $Y_{i j}$ é a observação da i-ésima espécie (i $=$ $1,2,3,4$ e 5) na j-ésima repetição $(j=1,2,3$ e 4); $\mu$ é uma constante inerente a todas as observações; $t_{i}$ é o efeito da i-ésima espécie $\left(\mathrm{i}=1,2,3,4\right.$ e 5); $e_{i j}$ é o erro experimental associado à observação $Y_{i j}$, independente e identicamente distribuído de uma Normal com média zero e variância $\sigma^{2}$.

Utilizou-se a análise multivariada de componentes principais (PCA) com o objetivo de explicar a estrutura de variância do vetor aleatório composto pelas características e propriedades avaliadas na madeira e no carvão das espécies estudadas. Foram consideradas apenas as médias de cada variável e a análise de componentes principais foi realizada considerando-se a matriz de correlação dos dados. Esse procedimento equivale a padronizar as variáveis e permite maior acurácia na análise (MINGOTI, 2005).

O número de componentes principais retidas foi determinado por meio do gráfico denominado scree plot, sendo que na abscissa encontram-se as componentes principais e na ordenada os autovalores que representam a variância estimada por cada componente principal (FERREIRA, 2008; MINGOTI, 2005).

As combinações lineares estabelecidas foram interpretadas por meio dos autovetores normalizados e das correlações entre as variáveis originais e as componentes principais.

Todas as análises estatísticas foram efetuadas utilizando-se o software estatístico $R$ versão 2.15.1, pacotes stats (R DEVELOPMENT CORE TEAM, 2012) e laercio (SILVA, 2010).

\section{RESULTADOS E DISCUSSÃO}

Na Tabela 1 encontram-se os valores médios de densidade básica e dos componentes químicos da madeira para as cinco espécies avaliadas, bem como o teste de comparação múltipla realizado. Observou-se pelo Teste $\mathrm{F}$ que o efeito da espécie foi significativo $(p<0,05)$ apenas para a densidade básica e para os teores de lignina insolúvel e holocelulose.

Quanto à densidade básica observa-se a formação de quatro grupos distintos, em que a espécie Trema micrantha apresentou o menor valor e a espécie Casearia sylvestris o maior. Essa característica da madeira é considerada fundamental na avaliação de espécies arbóreas, como clones de eucalipto, para a produção de bioenergia e carvão vegetal (PROTÁSIO et al., 2013).

Tabela 1- Valores médios das características avaliadas na madeira, bem como o teste de comparação múltipla realizado

Table 1-Average values of the characteristics evaluated in the wood, as much as the multiple comparison test performed

\begin{tabular}{cccccc}
\hline Espécies & DB & EXT & LIG* $^{*}$ & HOLO & CZ \\
\hline Casearia sylvestris & $0,625 \mathrm{~d}$ & $6,09 \mathrm{a}$ & $26,87 \mathrm{c}$ & $65,12 \mathrm{a}$ & $1,92 \mathrm{a}$ \\
Guazuma ulmifolia & $0,546 \mathrm{c}$ & $7,76 \mathrm{a}$ & $23,59 \mathrm{~b}$ & $67,11 \mathrm{a}$ & $1,53 \mathrm{a}$ \\
Rapanea ferruginea & $0,511 \mathrm{c}$ & $5,26 \mathrm{a}$ & $19,88 \mathrm{a}$ & $73,18 \mathrm{~b}$ & $1,69 \mathrm{a}$ \\
Trema micrantha & $0,364 \mathrm{a}$ & $5,78 \mathrm{a}$ & $22,68 \mathrm{~b}$ & $69,61 \mathrm{a}$ & $1,92 \mathrm{a}$ \\
Luehea divaricata & $0,475 \mathrm{~b}$ & $6,41 \mathrm{a}$ & $23,55 \mathrm{~b}$ & $68,11 \mathrm{a}$ & $1,93 \mathrm{a}$ \\
\hline CVe (\%) & 4,99 & 21,51 & 10,23 & 3,47 & 19,08 \\
\hline Média & 0,504 & 6,24 & 23,31 & 68,62 & 1,80 \\
\hline
\end{tabular}

DB: densidade básica $\left(\mathrm{g} / \mathrm{cm}^{3}\right)$; EXT, LIG, HOLO, CZ: teores de extrativos totais (\%), lignina insolúvel (\%), holocelulose e cinzas, respectivamente; CVe: coeficiente de variação experimental. Valores médios seguidos de mesma letra não diferem entre si pelo Teste de Scott-Knott em nível de 5\% de significância. *Aplicado o Teste Scott-Knott em nível de $10 \%$ de significância.

Trugilho et al. (2001), Neves et al. (2011), Reis et al. (2012a) e Protásio et al. (2013) encontraram densidade básica média para clones de Eucalyptus inferior ao observado neste trabalho para a espécie Casearia sylvestris. Esse resultado é um indicativo do potencial de uso dessa espécie para a produção de carvão vegetal e bioenergia e reforça a necessidade de estudos relacionados ao melhoramento genético dessa espécie para o seu uso bioenergético.

Vale, Brasil e Leão (2002), estudando a qualidade de madeiras do cerrado para fins energéticos, encontraram variação da densidade básica da madeira de $0,200 \mathrm{~g} / \mathrm{cm}^{3}$ a $0,780 \mathrm{~g} / \mathrm{cm}^{3}$. Pereira \& Lavoranti (1986), comparando a qualidade da madeira de três procedências de Mimosa scabrella encontraram densidade básica média de $0,537 \mathrm{~g} /$ $\mathrm{cm}^{3}$, assemelhando ao encontrado para a espécie Guazuma ulmifolia.

Quanto à composição química pode-se observar que a espécie Casearia sylvestris possui o maior teor de lignina, enquanto que a espécie Rapanea ferruginea possui o menor valor. As demais espécies formaram um grupo intermediário quanto a essa característica química da madeira.

Para o teor de holocelulose a espécie Rapanea ferruginea se destacou com o maior valor, sendo superior ao comumente encontrado para clones de Eucalyptus de 64 a $67 \%$ nas idades de 42 e 68 meses destinados ao uso energético (NEVES et al., 2011; PROTÁSIO et al.,

Cerne, Lavras, v. 20, n. 1, p. 37-46, jan./mar. 2014 
2013), respectivamente. Esse resultado não é benéfico para a produção de carvão vegetal, uma vez que as hemiceluloses e a celulose apresentam baixa estabilidade térmica em relação à macromolécula da lignina (RAAD et al., 2006; GANI \& NARUSE, 2007). Logo, maiores teores de holocelulose tendem a diminuir o rendimento em carvão vegetal (PROTÁSIO et al., 2012).

Observa-se que quanto maior o conteúdo de lignina menor será o teor de holocelulose, uma vez que a segunda característica mencionada é obtida por diferença. Isso também foi verificado por Vale et al. (2010) em experimento com espécies do cerrado. Os autores encontraram valores variando de 25,16 a $32,31 \%$ para o teor de lignina e 67,69 a $74,84 \%$ para a holocelulose para cinco espécies de ocorrência no bioma cerrado. Já Protásio et al. (2013) encontraram valores de lignina total para clones de Eucalyptus de 28,01 a 35,12\% superior a todas as espécies estudadas neste trabalho. Esse resultado deve-se ao efeito da espécie e ao melhoramento genético dos clones de eucalipto destinados a produção de carvão vegetal.

Para o teor de extrativos totais e cinzas não foi observado efeito significativo da espécie. Logo, essas características não podem ser utilizadas na seleção das espécies estudadas para a produção de carvão vegetal. Dependendo da composição química dos extrativos, bem como da sua estabilidade térmica, maiores valores são desejáveis, pois maximiza o rendimento em carvão vegetal (PROTÁSIO et al., 2012). Já o elevado teor de cinzas na madeira não é benéfico, pois, certamente, irá resultar em um carvão com elevado conteúdo de minerais.

Observou-se que o efeito da espécie foi significativo pelo Teste $\mathrm{F}(\mathrm{p}<0,05)$ para o rendimento em carvão vegetal, densidade relativa aparente e poder calorífico superior (Tabela 2).

Dentre as espécies estudadas a Luehea divaricata e Casearia sylvestris possuem os maiores rendimentos em carvão vegetal. Os valores médios do rendimento gravimétrico das espécies Trema micrantha, Guazuma ulmifolia e Rapanea ferruginea não diferiram entre si e formaram um único grupo.

Quanto ao rendimento em carbono fixo todas as espécies possuem estatisticamente o mesmo valor $(25,37 \%)$. Esse mesmo resultado foi observado por Assis et al. (2012) para um clone de um híbrido de Eucalyptus em diferentes idades e locais. Os autores mencionaram que esse resultado é um indicativo da baixa influência da matéria-prima nessa variável, pois o rendimento em
Tabela 2 - Valores médios de algumas características avaliadas no carvão vegetal

Table 2 - Average values of the some characteristics evaluated in the charcoal

\begin{tabular}{ccccc}
\hline Espécies & RGC (\%) & $\begin{array}{c}\text { DRA (g } \\
\left.\mathrm{cm}^{-3}\right)\end{array}$ & $\begin{array}{c}\text { PCS (kcal } \\
\left.\mathrm{kg}^{-1}\right)\end{array}$ & RCF (\%) \\
\hline Casearia sylvestris & $33,08 \mathrm{~b}$ & $0,475 \mathrm{c}$ & $7356 \mathrm{a}$ & $25,70 \mathrm{a}$ \\
Guazuma ulmifolia & $31,38 \mathrm{a}$ & $0,462 \mathrm{c}$ & $7456 \mathrm{~b}$ & $25,41 \mathrm{a}$ \\
Rapanea ferruginea & $30,88 \mathrm{a}$ & $0,366 \mathrm{~b}$ & $7524 \mathrm{~b}$ & $24,53 \mathrm{a}$ \\
Trema micrantha & $31,73 \mathrm{a}$ & $0,255 \mathrm{a}$ & $7730 \mathrm{~b}$ & $24,63 \mathrm{a}$ \\
Luehea divaricata & $34,39 \mathrm{c}$ & $0,386 \mathrm{~b}$ & $7135 \mathrm{a}$ & $26,56 \mathrm{a}$ \\
\hline CVe & 1,80 & 8,73 & 2,60 & 5,21 \\
\hline Média & 32,29 & 0,39 & 7440,2 & 25,37 \\
\hline
\end{tabular}

RGC: rendimento gravimétrico em carvão vegetal; DRA: densidade relativa aparente; PCS: poder calorífico superior; RCF: rendimento em carbono fixo. Valores médios seguidos de mesma letra não diferem entre si pelo Teste de Scott-Knott em nível de $5 \%$ de significância.

carbono fixo é obtido pelo produto do teor de carbono fixo e o rendimento gravimétrico em carvão vegetal e essas duas últimas variáveis apresentam correlação negativa, conforme relatado por Protásio et al. (2011).

$\mathrm{Na}$ literatura os valores de rendimento em carbono fixo variam entre de $25 \%$ a $27 \%$, aproximadamente, para vários clones e espécies de Eucalyptus (TRUGILHO et al. 2005; BOTREL et al., 2007; NEVES et al., 2011; REIS et al., 2012a; REIS et al., 2012b; ASSIS et al., 2012), corroborando com o encontrado no presente trabalho para o carvão vegetal produzido a partir da madeira das espécies avaliadas.

A lignina é o componente de maior influência na produção e qualidade do carvão. De acordo com Trugilho et al. (1997) e Protásio et al. (2012) quando uma madeira com alto teor de lignina é carbonizada o carvão vegetal oriundo desta madeira terá elevado rendimento, corroborando ao encontrado para as espécies Casearia sylvestris e Luehea divaricata. Contudo, a qualidade da lignina, ou seja, a relação siringil/guaiacil (S/G) também deve ser considerada.

As espécies Casearia sylvestris e Guazuma ulmifolia possuem os maiores valores para a densidade relativa aparente do carvão vegetal e também os maiores valores de densidade básica da madeira. Já a Trema micrantha possui os menores valores de densidade relativa aparente do carvão e densidade básica da madeira.

Conforme Vale et al. (2010) existe alta correlação entre densidade básica da madeira e a densidade aparente do carvão, ou seja, quanto maior for à densidade da madeira

Cerne, Lavras, v. 20, n. 1, p. 37-46, jan./mar. 2014 
mais denso será o carvão vegetal e maior será a quantidade de energia por unidade de volume desse biocombustível e menores serão os custos relacionados ao transporte tanto da madeira quanto do carvão. Além disso, quanto maior a densidade do carvão maior será a sua resistência mecânica nos altos fornos siderúrgicos.

Pode-se observar que dentre as espécies, a Trema micrantha situa-se no grupo que possui o maior poder calorífico no carvão vegetal. Contudo, a baixa densidade relativa aparente do carvão vegetal dessa espécie resulta em baixa densidade energética e baixa resistência a compressão desse biorredutor nos altos fornos siderúrgicos. Esses resultados demonstram que o uso dessa espécie pelo setor siderúrgico pode ser inviável tecnicamente.

Observa-se que o efeito das diferentes espécies foi significativo $(\mathrm{p}<0,05)$ apenas para o teor de cinzas, evidenciando maiores médias para as espécies Luehea divaricata e Casearia sylvestris (Figura 1). Observa-se ainda que a variabilidade do poder calorífico superior do carvão vegetal encontrada neste trabalho (Tabela 2) pode ser explicada pela diferença no teor de cinzas desse combustível, uma vez que os teores de materiais voláteis e carbono fixo não apresentaram diferença estatística.

Sabe-se que quanto maior o teor de cinzas menor será o poder calorífico do combustível, uma vez que as cinzas não participam do processo de combustão (BRAND, 2010; REIS et al., 2012b).

Para a utilização bioenergética do carvão vegetal deve-se analisar o teor de carbono fixo, de materiais voláteis e cinzas, pois essas características possuem significativas correlações com o poder calorífico e com o desempenho do carvão nos fornos siderúrgicos (PARIKH et al., 2005; THIPKHUNTHOD et al., 2005; MAJUMDER et al., 2008; PROTÁSIO et al., 2011; REIS et al., 2012b). Todas as espécies avaliadas possuem altos teores de carbono fixo e baixos teores de materiais voláteis, assemelhando ao encontrado por Trugilho et al. (2001) para diferentes clones de Eucalyptus.

Rosillo-Calle \& Bezzon (2005) afirmaram que o carvão vegetal usado na fabricação de aço e ferro-gusa deve ter um teor de carbono fixo superior a $75 \%$. Os resultados encontrados são indicativos da potencialidade de utilização do carvão vegetal dessas espécies na siderurgia e para a geração de bioenergia em gaseificadores, termelétricas ou outros sistemas de conversão energética.

Quanto ao teor de cinzas são comumente encontrados na literatura baixos valores $(0,16$ a $2 \%)$ para o carvão vegetal de vários clones e espécies de Eucalyptus
(TRUGILHO et al., 2001; SANTIAGO \& ANDRADE, 2005; TRUGILHO et al., 2005; BOTREL et al., 2007; NEVES et al., 2011; ASSIS et al., 2012; REIS et al., 2012a; REIS et al., 2012b), sendo que essas médias são inferiores ao encontrado para o carvão vegetal das espécies avaliadas.

Protásio et al. (2011) encontraram teor de cinzas para o carvão vegetal de Qualea parviflora de 2,93\% e superior ao relatado para clones de eucalipto, corroborando com este trabalho. Ainda nesse sentido, Vale et al. (2011) mencionaram que teores de cinzas superiores a 7\% são considerados elevados, o que não foi observado para o carvão vegetal ou a madeira das espécies estudadas.

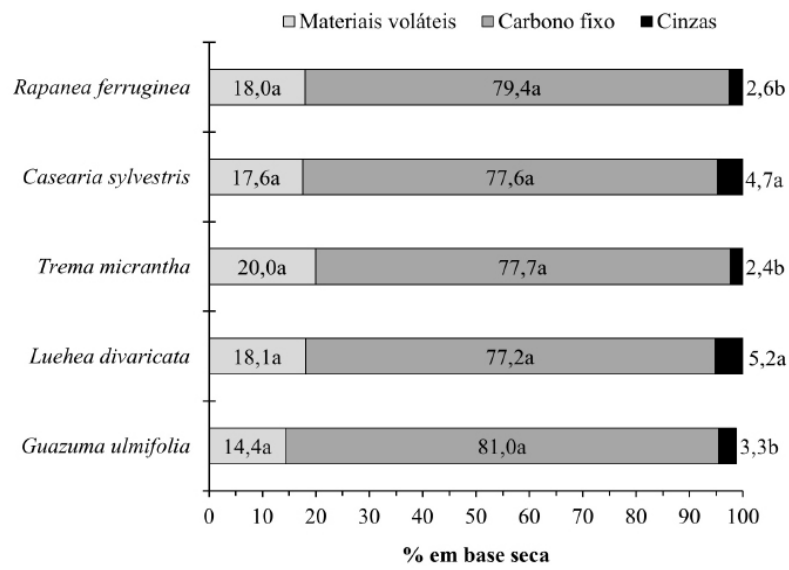

Médias seguidas pela mesma letra não diferem entre si em nível de 5\% de significância pelo Teste Scott-Knott.

Figura 1 - Análise química imediata do carvão vegetal.

Figure 1 - Proximate chemical analysis of the charcoal.

\subsection{Análise de componentes principais}

Observa-se que as duas primeiras componentes principais explicaram aproximadamente $83 \%$ da variância total (Tabela 3). Portanto, as informações mais relevantes dos dados amostrais originais estão contidas nessas duas componentes principais.

Quanto maiores os teores de lignina e cinzas no carvão vegetal, a densidade relativa aparente, o rendimento em carbono fixo e o rendimento gravimétrico em carvão vegetal menores serão os escores da primeira componente principal, uma vez que essas variáveis possuem as maiores contribuições e correlações negativas com essa componente. Já o teor de holocelulose e o poder calorífico superior do carvão vegetal apresentaram autovetores

Cerne, Lavras, v. 20, n. 1, p. 37-46, jan./mar. 2014 
Tabela 3 - Autovetores e as correlações entre as variáveis originais e as duas primeiras componentes principais

Table 3 - Eigenvectors and correlations between original variables and the first two principal components

\begin{tabular}{|c|c|c|c|c|c|c|c|}
\hline \multirow{2}{*}{ Material } & \multirow{2}{*}{ Características } & \multicolumn{3}{|c|}{ Componente principal 1} & \multicolumn{3}{|c|}{ Componente principal 2} \\
\hline & & ê1 & $\mathrm{r}$ & Cont & ê2 & $\mathrm{r}$ & Cont \\
\hline \multirow{5}{*}{ MADEIRA } & $\mathrm{DB}$ & $-0,260$ & $-0,63$ & 6,75 & 0,237 & 0,48 & 5,61 \\
\hline & Cinzas & $-0,094$ & $-0,23$ & 0,88 & $-0,471$ & $-0,95$ & 22,21 \\
\hline & Extrativos & $-0,204$ & $-0,49$ & 4,15 & 0,317 & 0,64 & 10,04 \\
\hline & Lignina & $-0,333$ & $-0,81$ & 11,12 & $-0,045$ & $-0,09$ & 0,20 \\
\hline & Holocelulose & 0,345 & 0,83 & 11,87 & $-0,033$ & $-0,07$ & 0,11 \\
\hline \multirow{7}{*}{$\begin{array}{l}\text { CARVÃO } \\
\text { VEGETAL }\end{array}$} & DRA & $-0,307$ & $-0,74$ & 9,40 & 0,288 & 0,58 & 8,28 \\
\hline & Voláteis & 0,159 & 0,38 & 2,53 & $-0,452$ & $-0,91$ & 20,39 \\
\hline & Cinzas & $-0,390$ & $-0,94$ & 15,22 & $-0,129$ & $-0,26$ & 1,67 \\
\hline & Carbono Fixo & 0,102 & 0,25 & 1,03 & 0,476 & 0,96 & 22,66 \\
\hline & $\mathrm{RCF}$ & $-0,377$ & $-0,91$ & 14,23 & $-0,088$ & $-0,18$ & 0,78 \\
\hline & RGC & $-0,326$ & $-0,79$ & 10,61 & $-0,281$ & $-0,57$ & 7,89 \\
\hline & PCS & 0,349 & 0,84 & 12,19 & 0,042 & 0,08 & 0,17 \\
\hline \multicolumn{2}{|c|}{ Variância Explicada (\%) } & & 48,76 & & & 34,17 & \\
\hline \multicolumn{2}{|c|}{ Variância acumulada (\%) } & & 48,76 & & & 82,94 & \\
\hline \multicolumn{2}{|c|}{ Autovalores } & & 5,85 & & & 4,10 & \\
\hline
\end{tabular}

$\hat{e} 1$ e ê2 : autovetores das componentes principais 1 e 2 , respectivamente; r: correlação entre as variáveis originais e as componentes principais; Cont: contribuições das variáveis nas componentes principais em porcentagem (\%); DB: densidade básica da madeira; DRA: densidade relativa aparente do carvão; RGC: rendimento gravimétrico em carvão vegetal; PCS: poder calorífico superior; RCF: rendimento em carbono fixo.

positivos.

Os resultados encontrados para a primeira componente principal indicam que os teores de lignina e holocelulose encontram-se associados positivamente e negativamente à densidade relativa aparente do carvão vegetal e os rendimentos em carbono fixo e em carvão vegetal, respectivamente. Vale et al. (2010) encontraram correlações positiva e negativa entre os teores de lignina e holocelulose com a densidade relativa aparente do carvão vegetal de espécies do cerrado, respectivamente, assemelhando-se as tendências encontradas nesse trabalho.

Quanto a segunda componente principal observase que os teores de cinzas na madeira e de materiais voláteis no carvão vegetal apresentaram autovetores e correlações negativas, enquanto o teor de carbono fixo apresentou associação positiva com essa componente principal. Além disso, observa-se que, apesar da menor contribuição, a densidade básica e a densidade relativa aparente apresentaram autovetores positivos, o que indica uma correlação entre essas variáveis. Quanto maior o teor de carbono fixo e a densidade relativa aparente do carvão vegetal maiores serão os escores dessa componente. Dessa forma, a segunda componente principal pode ser interpretada como um índice de qualidade do carvão vegetal para uso siderúrgico.

Na Figura 2 encontram-se o diagrama de ordenação das variáveis originais e os escores das duas primeiras componentes principais.

Observa-se que as espécies Casearia sylvestris e Luehea divaricata formaram um único grupo e possuem os maiores rendimentos em carvão vegetal e em carbono fixo, bem como os maiores teores de cinzas no carvão vegetal e o maior teor de lignina na madeira. Essas características foram as mais relevantes para o agrupamento dessas espécies.

Conforme os autovetores e escores das componentes principais pode-se observar que a espécie Trema micranta se destacou como um único grupo e possui elevados teores de holocelulose na madeira e de materiais voláteis no carvão vegetal e baixos teores de extrativos totais na madeira. Essa espécie possui ainda baixa densidade básica da madeira e baixa densidade relativa aparente do carvão. Esse resultado pode dificultar a utilização do carvão vegetal dessa espécie no setor siderúrgico.

Já a espécie Rapanea ferruginea se destacou pelo elevado poder calorífico superior do carvão vegetal, assemelhando-se a Trema micrantha. Contudo, a espécie Rapanea ferruginea pode ser considerada um grupo

Cerne, Lavras, v. 20, n. 1, p. 37-46, jan./mar. 2014 


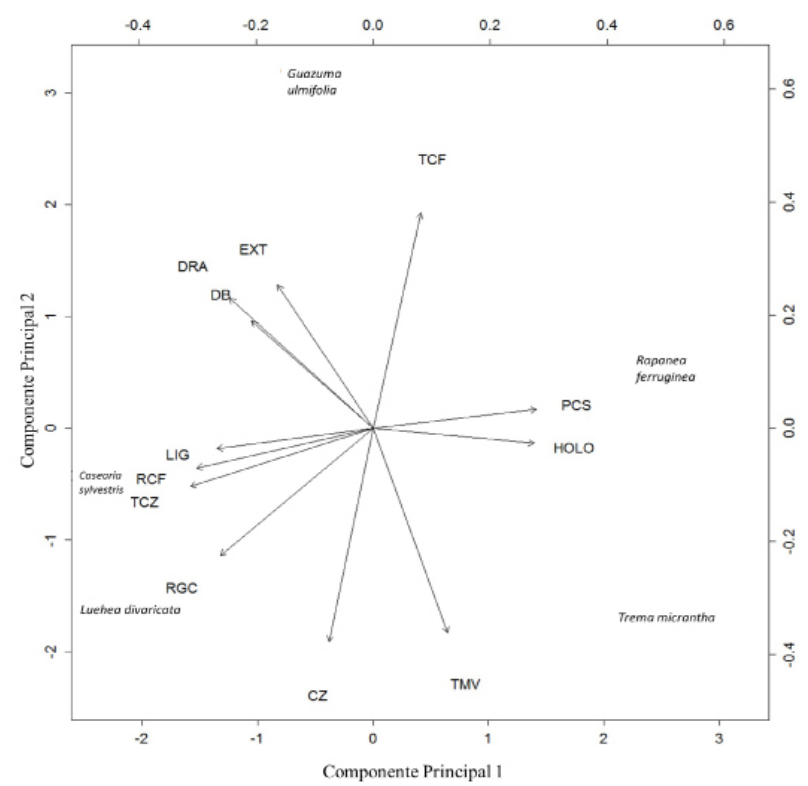

Características do carvão vegetal: TCF, TMV, TCZ: teores de carbono fixo, materiais voláteis e cinzas; DRA: densidade relativa aparente; RCF: rendimento em carbono fixo; RGC: rendimento gravimétrico em carvão vegetal; PCS: poder calorífico superior. Características da madeira: DB: densidade básica; LIG, EXT, HOLO, CZ: teores de lignina insolúvel, extrativos totais, holocelulose e cinzas, respectivamente.

Figura 2 - Diagrama de ordenação das variáveis originais e escores das duas primeiras componentes principais.

Figure 2 - Diagram of original variables ordination and scores of the first two principal components.

isolado, principalmente pelo elevado teor de holocelulose e baixo teor de lignina. Consequentemente, essa espécie também possui valores inferiores de rendimento em carvão vegetal e em carbono fixo em relação às demais espécies estudadas.

As espécies Guazuma ulmifolia e Casearia sylvestris se destacaram pelos maiores valores de densidade básica da madeira e de densidade relativa aparente do carvão vegetal. Contudo, o teor de carbono fixo do carvão vegetal foi a variável mais relevante na diferenciação da espécie Guazuma ulmifolia. Esses resultados demonstram o potencial de uso siderúrgico dessa espécie.

\section{CONCLUSÕES}

Os resultados obtidos demonstram o potencial de uso de espécies nativas do cerrado mineiro para a geração de bioenergia e carvão vegetal considerando como referência alguns clones/espécies do gênero Eucalyptus, com destaque para as espécies Casearia sylvestris, Guazuma ulmifolia e Luehea divaricata.

As espécies Casearia sylvestris e Luehea divaricata possuem os maiores rendimentos em carvão vegetal e em carbono fixo, bem como elevados teores de lignina na madeira.

As espécies Caseria sylvestris e Guazuma ulmifolia possuem os maiores valores de densidade básica da madeira e de densidade relativa aparente do carvão vegetal. A espécie Guazuma ulmifolia se destacou ainda pelo elevado teor de carbono fixo no carvão vegetal. Esses resultados indicam que essas espécies são as mais promissoras para a produção de carvão vegetal para uso na siderurgia.

Já para a espécie Rapanea ferruginea observouse baixo teor de lignina e elevado teor de holocelulose e rendimento em carvão inferior às demais espécies. Logo, com vistas à produção de carvão vegetal essa espécie não é a mais indicada, mesmo tendo apresentado carvão vegetal de densidade intermediária.

O carvão vegetal da espécie Trema micrantha possui elevado poder calorífico superior, mas a menor densidade relativa aparente e o maior teor de materiais voláteis. Dessa forma, esses resultados desclassificam essa espécie para a produção de carvão vegetal tanto para uso doméstico quanto siderúrgico.

\section{AGRADECIMENTOS}

Os autores agradecem à FAPEMIG e ao CNPq pelo apoio financeiro; ao CAPQ/UFLA pelo suporte técnico e ao Programa de Pós-Graduação em Ciência e Tecnologia da Madeira/UFLA.

\section{REFERÊNCIAS}

AGÊNCIA BRASIL. Indústrias que usam carvão vegetal do Cerrado terão até 2013 para comprar o produto de áreas reflorestadas. Disponível em: $<\mathrm{http}: / /$ www.agrosoft.org.br/agropag/213670.htm>. Acesso em: 11 out. 2013.

AMERICAN SOCIETY FOR TESTING MATERIALS. D 1762- 84: Standard test method for chemical analysis of wood charcoal. Philadelphia: ASTM International, 2007. 2p.

Cerne, Lavras, v. 20, n. 1, p. 37-46, jan./mar. 2014 
ANUÁRIO estatístico da ABRAF 2012: ano base 2011. Brasília, DF: ABRAF, 2012. 150 p.

ASSIS, M. R.; PROTÁSIO, T. P.; ASSIS, C. O.; TRUGILHO, P. F.; SANTANA, W. M. S. Qualidade e rendimentos do carvão vegetal de um clone híbrido de Eucalyptus grandis x Eucalyptus urophylla. Pesquisa Florestal Brasileira, Colombo, v. 32, n. 71, p. 291-302, 2012. DOI: $10.4336 / 2012$.pfb.32.71.291

ASSOCIAÇÃO BRASILEIRA DE NORMAS TÉCNICAS. NBR 11941: Madeira - determinação da densidade básica. Rio de Janeiro, 2003. 6 p.

ASSOCIAÇÃO BRASILEIRA DE NORMAS TÉCNICAS. NBR 8633: Carvão vegetal determinação do poder calorífico. Rio de Janeiro, 1984. 13 p.

ASSOCIAÇÃO BRASILEIRA TÉCNICA DE CELULOSE E PAPEL. M11/77: Teor de cinzas. São Paulo, Brasil, 1974b. 8 p.

ASSOCIAÇÃO BRASILEIRA TÉCNICA DE CELULOSE E PAPEL. M3/69: Métodos de ensaio. São Paulo, Brasil, 1974a. 8 p.

ASSOCIAÇÃO BRASILEIRA TÉCNICA DE CELULOSE E PAPEL. M70/71: Métodos de ensaio. São Paulo, Brasil, 1974.

BOTREL, M. C. G.; TRUGILHO, P. F.; ROSADO, S. C. S.; SILVA, J. R. M. Melhoramento genético das propriedades do carvão vegetal de Eucalyptus. Revista Árvore, Viçosa, v. 31, n. 3, p.391-398, 2007.

BRASIL. Ministério de Minas e Energia. Balanço energético nacional. Brasília, 2010. 59 p.

FERREIRA, D. F. Estatística Multivariada. Lavras: UFLA, 2008. 662p.

GANI, A.; NARUSE, I. Effect of cellulose and lignin content on pyrolysis and combustion characteristics for several types of biomass. Renewable Energy, Oxford, v. 32, n. 4, p. 649-661, 2007.

MAJUMDER, A. K.; JAIN, R.; BANERJEE, P.; BARNWAL, J. P. Development of a new proximate analysis based correlation to predict calorific value of coal. Fuel, London, v. 87, n. 13-14, p. 3077-3081, 2008.

MINISTÉRIO DO MEIO AMBIENTE. Plano de ação para prevenção e controle do desmatamento e das queimadas: Cerrado. Brasília: MMA, 2011. 200 p.

MINGOTI, S. A. Análise de dados através de métodos de estatística multivariada: uma abordagem aplicada. Belo Horizonte: UFMG, 2005. 297p.

MUÑIZ, G. I. B; NISGOSKI, S.; SHARDOSIN, F. Z.; FRANÇA, R. F. Anatomia do carvão de espécies florestais. Cerne, Lavras, v. 18, n. 3, p. 471-477, 2012.

NEVES, T. A.; PROTÁSIO, T. P.; COUTO, A. M.; TRUGILHO, P. F.; SILVA, V. O.; VIEIRA, C. M. M. Avaliação de clones de Eucalyptus em diferentes locais visando à produção de carvão vegetal. Pesquisa Florestal Brasileira, Colombo, v. 31, n. 68, p. $319-$ 330, 2011. DOI: 10.4336/2011.pfb.31.68.319

PARIKH, J.; CHANNIWALA, S. A.; GHOSAL, G. K. A correlation for calculating HHV from proximate analysis of solid fuels. Fuel, London, v. 84, n. 5, p. 487-494, 2005.

PEREIRA, J. C. D.; LAVORANTI, O. J. Comparação da qualidade da madeira de três procedências de Mimosa scabrella Benth. para fins energéticos. Boletim de Pesquisa Florestal, Curitiba, v. 12, p. 30-34, 1986.

PROTÁSIO, T. P.; COUTO, A. M.; REIS, A. A.; TRUGILHO, P. F. Seleção de clones de Eucalyptus para a produção de carvão vegetal e bioenergia por meio de técnicas univariadas e multivariadas. Scientia Forestalis, Piracicaba, v. 42, n. 97, 2013.

PROTÁSIO, T. P.; SANTANA, J. D. P.; GUIMARÃES NETO, R. M.; GUIMARÃES JÚNIOR, J. B.; TRUGILHO, P. F.; RIBEIRO, I. B. Avaliação da qualidade do carvão vegetal de Qualea parviflora. Pesquisa Florestal Brasileira, Colombo, PR, v. 31, n. 68, p. 295-07, 2011b. DOI: 10.4336/2011.pfb.31.68.295

PROTÁSIO, T. P.; TRUGILHO, P. F.; NEVES, T. A.; VIEIRA, C. M. M. Análise de correlação canônica entre características da madeira e do carvão vegetal de Eucalyptus. Scientia Forestalis, Piracicaba, v. 40, n. 95,

Cerne, Lavras, v. 20, n. 1, p. 37-46, jan./mar. 2014 
p. $317-326,2012$.

RAAD, T. J.; PINHEIRO, P. C. C.; YOSHIDA, M. I. Equação geral de mecanismos cinéticos da carbonização do Eucalyptus spp. Cerne, Lavras, v. 12, n. 2, p. 93-106, 2006.

R DEVELOPMENT CORE TEAM. R: A language and environment for statistical computing. Vienna, Austria: R Foundation for Statistical Computing, 2012. $\mathrm{R}$ version 2.15.1. Disponível em: <http://www.R-project. org >. Acesso em: 14 out. 2012.

REIS, A. A.; MELO, I. C. N. A.; PROTÁSIO, T. P.; TRUGILHO, P. F.; CARNEIRO, A. C. Efeito de local e espaçamento na qualidade do carvão vegetal de um clone de Eucalyptus urophylla S. T. Blake. Floresta e Ambiente, Seropédica, v. 19, n. 4, p.497-505, 2012a. DOI: 10.4322 /floram.2012.055

REIS, A. A.; PROTÁSIO, T. P.; MELO, I. C. N. A.; TRUGILHO, P. F.; CARNEIRO, A. C. Composição da madeira e do carvão vegetal de Eucalyptus urophylla em diferentes locais de plantio. Pesquisa Florestal Brasileira, Colombo, v. 32, n. 71, p. 277-290, 2012b. DOI: $10.4336 / 2012 . p f b .32 .71 .277$

ROSILLO-CALLE, F.; BEZZON, G. Produção e uso industriais do carvão vegetal. In: ROSILLO-CALLE, F.; BAJAY, S. V.; ROTHMAN, H. Uso da biomassa para a produção de energia na indústria brasileira. Campinas, SP: Unicamp, 2005. 447 p.

SANTIAGO, A. R.; ANDRADE, A. M. Carbonização de resíduos do processamento mecânico da madeira de eucalipto. Ciência Florestal, Santa Maria, v. 15, n. 1, p. $1-7,2005$.

SANTOS, R. C.; ANGÉLICA DE CÁSSIA OLIVEIRA CARNEIRO, A. C. O.; TRUGILHO, P. F.; MENDES, L. M.; CARVALHO, A. M. M. L. Análise termogravimétrica em clones de eucalipto como subsídio para a produção de carvão vegetal. Cerne, Lavras v.18, n. $1,2012$.

SILVA, L. J. Laercio: Duncan test, Tukey test and Scott-Knott test. R package version 1.0-1. 2010. Disponível em: http://cran-r.c3sl.ufpr.br/. Acesso em: 11 abril 2013.

THIPKHUNTHOD, P.; MEEYOO, V.; RANGSUNVIGIT, P.; KITIYANAN, B.;
SIEMANOND, K.; RIRKSOMBOON, T. Predicting the heating value of sewage sludges in Thailand from proximate and ultimate analyses. Fuel, London, v. 84, n. 7-8, p. 849-857, 2005.

TRUGILHO, P. F.; LIMA, J. T.; MORI, F. A; LINO, A. L. Avaliação de clones de Eucalyptus para a produção de carvão vegetal. Cerne, Lavras, v. 7, n. 2, p. 104 - 114, 2001.

TRUGILHO, P. F.; SILVA, J. R. M.; MORI, F. A.; LIMA, J. T.; MENDES, L. M.; MENDES, L. F. B. Rendimentos e características do carvão vegetal em função da posição radial de amostragem em clones de Eucalyptus. Cerne, Lavras, v. 11, n. 2, p. 178-186, 2005.

TRUGILHO, P. F.; VITAL, B. R.; REGAZZI, A. J.; GOMIDE, J. L. Aplicação da análise de correlação canônica na identificação de índices de qualidade da madeira de eucalipto para a produção de carvão vegetal. Revista Árvore, Viçosa, MG, v. 21, n. 2, p. 259-267, 1997.

VALE, A. T.; BRASIL, M. A. M.; LEÃO, A. L. Quantificação e caracterização energética da madeira e casca de espécies do cerrado. Ciência Florestal, Santa Maria, v. 12, n. 1, p. 71-80, 2002.

VALE, A. T.; DIAS, I. S.; SANTANA, M. A. E. Relação entre as propriedades químicas, físicas e energéticas da madeira de cinco espécies do cerrado. Ciência Florestal, Santa Maria, v. 20, n.1, p. 137- 145, 2010.

VALE, A. T.; MENDES, R. M.; AMORIM, M. R. S.; DANTAS, V. F. S. Potencial energético da biomassa e carvão vegetal do epicarpo e torta de pinhão manso (Jatropha curcas). Cerne, Lavras, v. 17, n. 2, p. 267273, 2011.

Recebido: 28 de junho de 2011; aceito: 01 de julho de 2013.

Cerne, Lavras, v. 20, n. 1, p. 37-46, jan./mar. 2014 
